\title{
3D-electron microscopic characterization of interstitial cells in the human bladder upper lamina propria.
}

Jochen Neuhaus ${ }^{1)^{\star}}$, Birgit Schröppel2), Martin Dass ${ }^{3) \S}$, Hans Zimmermann ${ }^{3)}$, Hartwig

Wolburg ${ }^{4)}$, Petra Fallier-Becker ${ }^{4)}$, Thomas Gevaert5), Claus J Burkhardt ${ }^{2)}$, Hoang

Minh Do6), Jens-Uwe Stolzenburg6)

1) University Leipzig, Department of Urology, Leipzig, Germany

2) Natural and Medical Sciences Institute (NMI) at the University of Tuebingen, Reutlingen, Germany

3) Carl Zeiss Microscopy GmbH, Training, Application and Support Center (TASC) Application Support EM, Munich, Germany

4) University Hospital Tuebingen, Institute of Pathology and Neuropathology, Tuebingen, Germany

5) KU Leuven, Laboratory of Experimental Urology, Department of Development and Regeneration, Leuven, Belgium

6) University Leipzig, University Hospital Leipzig, Department of Urology, Leipzig, Germany

${ }^{\S}$ current address: Boehringer Ingelheim Pharma GmbH \& Co. KG Development Germany, Biberach/Riss, Germany

${ }^{*}$ corresponding author:

Jochen Neuhaus, Ph.D., adj. Prof.

Department of Urology, Research Laboratory

University of Leipzig

Liebigstr. 19, Building C

04103 Leipzig

Germany

phone: +493419717688

Fax: +493419717659

email jochen.neuhaus@medizin.uni-leipzig.de

Running title: 3D-ultrastructure of the human bladder

This is the peer reviewed version of the following article: Neuhaus, Jochen; Schröppel, Birgit; Dass, Martin; Zimmermann, Hans; Wolburg, Hartwig; Fallier-Becker, Petra et al. (2017): 3D-electron microscopic characterization of interstitial cells in the human bladder upper lamina propria. In: Neurourology and urodynamics. DOI: 10.1002/nau.23270.,

which has been published in final form at [http://dx.doi.org/ 10.1002/nau.23270]. This article may be used for non-commercial purposes in accordance with Wiley Terms and Conditions for Self-Archiving. 


\section{Abstract:}

\section{1) Aims}

To explore the ultrastructure of interstitial cells in the upper lamina propria of the human bladder, to describe the spatial relationships and to investigate cell-cell contacts.

\section{2) Methods}

Focused ion beam scanning electron microscopy (FIB-SEM), 3-View SEM and confocal laser scanning microscopy were used to analyze the 3D ultrastructure of the upper lamina propria in male and female human bladders.

\section{3) Results}

3View-SEM image stacks as large as $59 \mu \mathrm{m} \times 59 \mu \mathrm{m} \times 17 \mu \mathrm{m}(\mathrm{xyz})$ at a resolution of $16 \mathrm{~nm} \times 16 \mathrm{~nm} \times 50 \mathrm{~nm}$ and high resolution (5nm $\times 5 \mathrm{~nm} \times 10 \mathrm{~nm})$ FIB-SEM stacks could be analyzed. Interstitial cells with myoid differentiation ( $\mathrm{mIC}$ ) and fibroblast like interstitial cells $(\mathrm{flC})$ were the major cell types in the upper lamina propria. The flat, sheet-like ICs were oriented strictly parallel to the urothelium. No spindle shaped cells were present. We furthermore identified one branched cell (bIC) with several processes contacting urothelial cells by penetrating the basal membrane. This cell did not make any contacts to other ICs within the upper lamina propria. We found no evidence for the occurrence of telocytes in the upper lamina propria.

\section{4) Conclusions}

Comprehensive 3D-ultrastructural analysis of the human bladder confirmed distinct subtypes of interstitial cells. We provide evidence for a foremost unknown direct connection between a branched interstitial cell and urothelial cells of which the functional role has still to be elucidated. 3D-ultrastructure analyses at high resolution are needed to further define the subpopulations of lamina propria cells and cell-cell interactions. 


\section{Abbreviations:}

$\mathrm{BL}=$ basal lamina

$\mathrm{BM}=$ (urothelial) basal membrane

$\mathrm{flC}=$ fibroblast type interstitial cell

$\mathrm{mIC}=$ myoid interstitial cell

bIC = branched interstitial cell

UC = urothelial cell

rER = rough endoplasmic reticulum

$\mathrm{sER}=$ smooth endoplasmic reticulum

GJ = gap junction

ULP = upper lamina propria

aSMCA = alpha smooth muscle cell actin

FIB-SEM = focused ion beam scanning electron microscopy 


\section{Introduction:}

Urinary bladder cellular composition is of utmost importance for the understanding of normal and pathological bladder function. There is a growing awareness of the heterogeneity of cells comprising the bladder wall regarding structure, immunological characteristics and receptor expression ${ }^{1}$. While urothelial contribution to proper bladder function is well defined by establishing urine-tissue barrier and serving as sensor for bladder filling, the function of the interstitial cells, representing the clear majority of cells within the lamina propria, is less well understood. They have been implicated in afferent signal processing because of their close association with sensory neurons, their receptor expression and their physiological properties ${ }^{2,3}$. Recent studies demonstrated that there is a considerable heterogeneity between those cells and subpopulations were defined based on morphological and immunohistochemical features ${ }^{4}$.

We investigated the ultrastructure and cell-cell interactions of ICs in the upper lamina propria (ULP) of the human bladder, since this region is of utmost significance for afferent signaling in the bladder. We included 3D-reconstructions from FIB-SEM (Focused ion beam - scanning electron microscopy) and Zeiss 3View field emission SEM technology. Those results were compared to high resolution 3D-reconstructions of confocal laser scanning microscopic image stacks.

\section{Material and Methods:}

\section{Ethics statement}

The study was approved by the Ethics Committee of the University of Leipzig (Reg.No.: 036/07lk; 773) and was conducted per the principles expressed in the Declaration of Helsinki. Written informed consent was obtained from all patients. Tissue samples acquired during routine transurethral resection of the bladder or after radical cystectomy.

\section{Electron microscopy}

3View-SEM: Specimens (84 yrs. old male) were fixed in $2 \%$ paraformaldehyde and $2.5 \%$ glutaraldehyde in $0.15 \mathrm{~mol} / \mathrm{l}$ cacodylate buffer $(\mathrm{pH} 7.4)$ supplemented with $2 \mathrm{mM}$ calcium chloride, processed for heavy metal contrast enhancement and embedded in Durcupan ${ }^{\circledR}$ ACM resin (Sigma-Aldrich, Steinheim, Germany) following a protocol of 


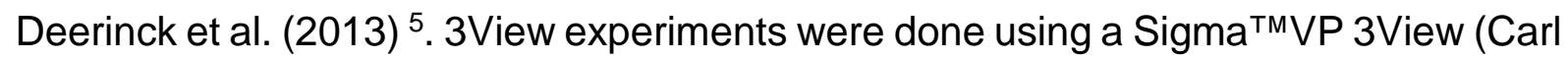
Zeiss, Munich, Germany). 3D stacks were imaged with a low kV sensitive backscattered detector 3vBSD, using an accelerating voltage between $0.9 \mathrm{kV}$ and 1.2 $\mathrm{kV}$ in the high current mode. Image sizes of $2 \mathrm{k}, 4 \mathrm{k}$ and $8 \mathrm{k}$ were realized.

FIB-SEM: Specimens (79 yrs. old male) was fixed in $2 \%$ glutaraldehyde in $0.1 \mathrm{M}$ cacodylate buffer ( $\mathrm{pH} 7.4)$. After that, the cells were postfixed in $1 \%$ buffered OsO4, washed in cacodylate buffer and stepwise dehydrated in ethanol. The $70 \%$ ethanol was saturated with uranyl acetate for contrast enhancement. Dehydration was completed in propylene oxide and specimens were embedded in Araldite ${ }^{\circledR}$ (Serva, Heidelberg, Germany). FIB-SEM stacks were scanned at a Crossbeam ${ }^{\circledR}$ Auriga 40 (NMI, Reutlingen) and a Crossbeam ${ }^{\circledR}$ Auriga 60 (Zeiss, Munich). We acquired electron microscopic serial image stacks of up to 1000 images. The minimum voxel resolution was $4.5 \times 4.5 \times 10 \mathrm{~nm}$. Image stacks were pre-processed using ImageJ and 3Dreconstructions were done with Amira ${ }^{\circledR} 3 \mathrm{D}$ Image Analysis software 5.0 - 6.1.1 (vsg, Düsseldorf, Germany) on a Mac Pro workstation (Apple Inc., Cupertino, CA, USA).

\section{Immunohistochemistry}

Ten to thirty $\mu \mathrm{m}$ thick paraffin sections of unaltered bladder tissue from two male (72y, 65y) and one female (53y) bladder tumor patients were used for multiplex immunofluorescence. We used anti-smooth muscle cell actin antibody to identify interstitial cells with myoid differentiation $(\mathrm{mIC})$, anti-connexin 43 to depict gap junctions (GJ), and an antibody against the ED-A domain of fibronectin to label cellular fibronectin for identification of fibronexus (Table S1). All labelings were also combined with Alexa Fluor ${ }^{\circledR}$ 488-labelled wheat germ agglutinin (WGA488) to depict cellular membranes (supplemental Methods 1).

Confocal laser scanning image stacks were acquired at a LSM 700 (Carl Zeiss Microscopy, Göttingen, Germany) equipped with 405nm, 488nm, 555nm and 639nm laser diodes. Stack sizes varied between 60 and 80 images. Image deconvolution and 3D-reconstruction were done with Huygens Essential imaging software package (SVI Scientific Volume Imaging, Hilversum, The Netherlands) or imageJ ${ }^{6}$. 


\section{Results:}

Cells in the ULP were embedded in massive collagen containing extracellular matrix (Fig. 1A). The urothelial basal membrane (BM) showed a characteristic layering comprised of amorphous material (Fig. 1B). The BM underlying the urothelium was clearly definable, about 1-2 $\mu \mathrm{m}$ thick and composed of amorphous and fibrous material. Mitochondria (M) were heavily contrasted but inner membranes were discernible in most cases (Fig. 1B).

3D-reconstruction of single cells revealed 17 interstitial cells: five fibroblast type IC $(\mathrm{flC})$, ten interstitial cells with myoid differentiation $(\mathrm{mIC})$, one lymphocyte, and one branched cell sharing some morphological and ultrastructural features with interstitial cells of Cajal, i.e. small nucleus, small cell body, 3 first level branches, accumulation of mitochondria within the branching points, discontinuous basal lamina) (Fig. 1C). The mIC all showed a flat, sheet-like morphology with the flattened surface facing the urothelium.

Fibroblast type Interstitial Cells (fIC)

Fibroblasts (Fig. 2) were characterized by:

(1) a sheet-like body with prominent cytoplasm

(2) sheet-like slender processes

(3) abundance of mitochondria

(4) prominent rER and SER

(5) absence of basal lamina

(6) absence of microfilament bundles

(7) absence of fibronexus type adhesion plaques

(8) absence of inter-cellular junctions.

Most interestingly, we found clear evidence for intra-cellular, 'homocytic' junctions between the protrusions of a $\mathrm{flC}$ closely associated to a second $\mathrm{flC}$ in a high resolution ( $5 \mathrm{~nm} \times 5 \mathrm{~nm} \times 10 \mathrm{~nm}$ voxel size) FIB-SEM stack (990 serial slices) of a $79 \mathrm{yrs}$. old patient (Fig. 3F-K). We identified gap junctions (GJ) between membrane protrusions. However, those GJ proved to connect protrusions of one and the same cell as revealed by tracking the two cell protrusions in continuous section series (Fig. $3 \mathrm{H}-\mathrm{J}$ ). 
Myoid Interstitial Cells ( $\mathrm{mIC}$ )

Interstitial cells with myoid differentiation were characterized by:

(1) sheet-like morphology

(2) sheet-like slender processes

(3) little and small mitochondria (Fig. 3A-B)

(4) little rER and SER

(5) absence of basal lamina

(6) microfilament bundles (Fig. 3C, arrows)

(7) fibronexus type adhesion plaques (Fig. 3D).

(8) frequent GJs (Fig. 3E; Table S2)

(9) no adherens junctions

\section{Branched IC (bIC)}

We found a unique cell located in parallel to the urothelial layer embedded in huge amounts of collagen. The cell body was small and the cell possessed 3 thick first level cell branches and several second and third level branches (Fig. 4). The bIC was covered by an interrupted basal lamina, while fICs and mICs did not show basal laminae (Fig. 4 A). The bIC was closely opposed to the urothelium as depicted in figure 4 B. Mitochondria were located within the branching points of the bIC (Fig. 4 C). Thereby the cell morphology was completely different from all other cells found within the tissue block. Most interestingly, this cell was the only one making tiny junction-like contacts to urothelial cells as revealed by high resolution 3D-analysis (Fig. 4 D-E).

The results of the detailed 3D-analysis of ICs in one $59 \mu \mathrm{m} \times 59 \mu \mathrm{m} \times 17 \mu \mathrm{m}$ tissue block are summarized in Table S2. We identified $10 \mathrm{mICs}, 5 \mathrm{fICs}$, one lymphocyte and one bIC. We did not find any telocyte-like cells or cell fragments meeting the criteria defined by Faussone Pellegrini and Popescu (2011) 7: (i) small cell body, (ii) scarce cytoplasm, (iii) variable number of long, convoluted prolongations, (iv) homocytic junctions, (v) so-called podomers and podoms. Supplemental Video S1 illustrates the findings by visualization of 3D-reconstruction of 10 cells from 3View-SEM of the tissue block $(59 \times 59 \times 17 \mu \mathrm{m})$ shown in Figure 1 . 
We used antibody and membrane fluorescence labeling by WGA488 to validate our ultrastructural findings. Alpha-smooth muscle cell actin (aSMCA) was confined to the plasma membrane (Fig. 5), which is in good agreement with the ultrastructural findings of sub-plasmalemmal microfilament bundles (Fig. $3 \mathrm{C}$ ). While mICs in the ULP showed a predominantly spindle shaped morphology by aSMCA labeling, WGA labeling revealed the flat cell morphology in agreement with the ultrastructural 3Dreconstructions (Fig. 5 B; Supplemental Video S2).

We further analyzed the expression of the gap junction protein Cx43 to support our ultrastructural findings of GJs between mICs. Small Cx43+ spots co-located with WGA (Fig. 5C-D, arrows) and were abundant between mIC but only space between urothelial cells (Fig. 5D, open arrows).

Extracellular domain EDA of cellular fibronectin (FNEDA), characteristic for myofibroblasts differentiation, was significantly expressed in ULP ICs but not in urothelium (Fig. 5 E-F). The labeling was colocalized or closely associated with WGA stained plasma membranes (Fig. $5 \mathrm{~F}$, arrows). We also confirmed FNEDA labeling in detrusor smooth muscle cells as described in literature ${ }^{8}$ (supplemental Fig. S1).

\section{Discussion}

During the past decade block face imaging SEM-technology has been successfully adopted to biologic specimens. Improvement of imaging quality, long term stability of stack acquisition and development of software tools for large area scanning, e.g. ATLAS (Zeiss) have rendered SEM into a valuable approach to three-dimensional analysis of tissue ultrastructure. In addition, the 3-View technology (Zeiss) integrating an ultramicrotome into a SEM column allows highly stable automatic serial section acquisition at z-resolutions of down to $15-20 \mathrm{~nm}$. In conjunction with ATLAS scanning areas of 32000 by 32000 pixels are possible. Limiting factors are the required stability of the system over several days, data volumes in the range of several hundreds of gigabytes up to terabytes, and high demands on image processing power. For data processing and three-dimensional analysis and reconstruction we used Amira 5.0 to version 6.1 (FEI SAS, Mérignac, France) allowing data processing of up to 300 GB by conversion of the image stacks to large data access (LDA) format.

Especially high voxel resolution is needed for the analysis of intercellular junctions. By construction the 3-View system is restricted to a minimal slice thickness of $15-20 \mathrm{~nm}$. However, in real world application 30-50 nm seem to be more practicable. We received 
good results at a voxel size of $16 \mathrm{~nm} \times 16 \mathrm{~nm}(\mathrm{XY})$ and $50 \mathrm{~nm}(\mathrm{Z})$, and succeeded to scan a volume of $59 \mu \mathrm{m} \times 59 \mu \mathrm{m} \times 17 \mu \mathrm{m}$ (Fig. 1). The resolution allowed the detection of $\mathrm{GJs}$ between $\mathrm{mIC}$ (Fig. 3E).

Higher resolutions (at smaller total tissue volume) are achievable using FIB-SEM. We reached $2.5 \mathrm{~nm} \times 2.5 \mathrm{~nm}(\mathrm{XY})$ and $5 \mathrm{~nm}(\mathrm{Z})$ axis resolution at best and we succeeded in scanning a volume of $15 \mu \mathrm{m} \times 11 \mu \mathrm{m} \times 10 \mu \mathrm{m}$ at a voxel size of $5 \mathrm{~nm} \times 5 \mathrm{~nm}(\mathrm{xy}) \times$ $10 \mathrm{~nm}(\mathrm{z})$ (Fig. 3F-K).

By combination of both methods we could examine the morphology of the interstitial cells within the human bladder and to analyze intercellular junctions in detail.

Despite we looked especially for telocytes, we did not find any telocyte protrusions in the ULP. All telocyte-suspect processes, characterized by a small diameter and interrupted in continuity, turned out to be part of a large cell surface.

Characterization of bladder interstitial cells is still under discussion. While fibroblasts are thought to have a sheet-like cell body with very thin, broad processes, myofibroblasts are regarded as spindle-shaped or stellate cells. This might in part be due to light microscopy and immunohistochemistry being the basis of the cell characterization. 3D-ultrastructural investigations of the ULP ICS and the ULPurothelial interface are, however, missing so far.

Our results clearly favor a different view:

1. There are two types of ICs within the lamina propria, the fibroblast type IC (fIC) and the myoid type IC ( $\mathrm{mIC})$.

2. The mICs possess a flat, sheet-like morphology and are arranged in stacks oriented in parallel to the urothelial layer. Thus, mICs present their maximum surface towards the bladder lumen, supporting the hypothesis, that those cells detect humoral signaling from urothelial cells ${ }^{3,9}$.

3. Myoid ICs are interconnected by gap junctions (inset Fig. 5D), indicating the formation of functional syncytia ${ }^{10,11}$. Heterocellular junctions between $\mathrm{mIC}$ and $\mathrm{flC}$ were not found. 3D-immunofluorescence analysis demonstrated numerous Cx43 positive particles, associated with cell membranes and located between ULP ICs (Fig. 5C-D).

4. Myoid ICs express FNEDA, which is a characteristic component of the fibronexus of myofibroblasts, especially found in reactive and tumoral myofibroblasts ${ }^{12}$. Thus, they resemble myofibroblasts, although ultrastructural 
appearance of fibronexus is not as pronounced as in activated myofibroblasts (inset Fig. 5E). Constitutive expression of the FNEDA domain may also be of functional relevance, since it can activate toll-like receptor 4 (TLR4) ${ }^{13}$ and is crucial for TGFß induced myofibroblast differentiation ${ }^{14}$.

5. The flCs had more pronounced cell bodies and thicker cellular protrusions. In one specimen (84 yrs. old male) those cells were filled with lipofuscin granules, which might be a sign of ageing (Fig. 2C).

6. We did not find c-kit ${ }^{+}$interstitial Cells of Cajal (ICCs) in the ULP as recently reported by our group ${ }^{15}$, but the bIC shared some ultrastructural features with ICCs (partly coverage by basal lamina, small cell body, several thick branching processes with mitochondria localized at the branching points). The bIC in our specimen penetrated the BM of the urothelium and made budding contacts to urothelial cells (Fig. 4). Those junctions could be interpreted as GJs.

Are there true myofibroblast in the ULP of the human bladder?

There is an ongoing discussion about the occurrence of true myofibroblasts in the bladder. The key feature of those essentially reactive cells is the fibronexus ${ }^{12}$. We found myoid ICs with variable amounts of microfilaments (MF) and variable formation of ultrastructural fibronexus (Table S2), supporting the view that at least part of the cell population showed myofibroblast features and may therefore be regarded as reactive mICs.

Are there interstitial cells of Cajal-like cells in the ULP of the human bladder?

Besides others Rasmussen et al. nicely demonstrated ICC-like cells in between the smooth muscle cell fascicles of the human detrusor by TEM ${ }^{16}$. The morphology and ultrastructural features of those were clearly different from the cells we analyzed in the ULP. In contrast, we found similar cells in SEM stacks from detrusor (data not shown). The branched IC we identified also clearly differed from the ICC-L especially by its smooth surface structure without dense bands or caveolae. Therefore, our current material does not support the incidence of ICC-like cells in the ULP of the human bladder.

Are there telocytes (TC) in the upper lamina propria of the human bladder? 
The "most peculiar feature of telocytes" is the "long, thin, and convoluted prolongations named telopodes" ${ }^{7}$. While prototypic TC have been demonstrated in many tissues, the cells termed TC in the ULP may form a distinct subset for differences in marker expression and ultrastructural features ${ }^{4}$. Indeed, in the present study using extensive 3D-reconstruction at ultrastructural level we did not find any telocyte in the examined tissues. As pointed out by Rusu et al. the telopodes should emerge from the cell body as thin processes - cells with processes becoming gradually thinner are not to be considered TC ${ }^{17}$. In single plane the thin, flat cell body of $\mathrm{mIC}$ might occasionally be misinterpreted as telopodes. We always found thin, flat, pancake-like cell morphology when reconstructing those membranes. Therefore, our data do not support the occurrence of telocytes in the ULP.

\section{Functional aspects}

The overall morphology and spatial orientation of $\mathrm{mIC}$ speak in favor of the notion that those cells are important players in the afferent signaling cascade $1,2,18,19$. The cells are stacked in parallel to the urothelium for maximum membrane presentation. Thus, they would be optimal positioned to sense humoral factors released by the urothelium, e.g. ATP during bladder filling. Pathophysiological relevance of altered purinergic signaling in functional bladder disorders is very likely ${ }^{20}$ and high sensitivity to ATP has been demonstrated in cell culture, already ${ }^{3}$. GJ-coupling of mICs enables spreading of the generated signals and may trigger detrusor contraction ${ }^{21}$ and modulation of functional syncytia activity due to altered connexin expression patterns could be a critical point in pathophysiology of overactive bladder (OAB), bladder outlet obstruction (BOO) and interstitial cystitis ${ }^{11,22}$.

Recently, two distinct phenotypes have been described for the ICs in the human bladder. Interestingly, the authors identified interstitial cell of Cajal-like cells by electron microscopy in the deeper lamina propria (DLP) only, while the ULP was mainly populated by ICs with myoid differentiation (vimentin+, aSMCA+) ${ }^{4}$. In addition, interstitial cells in the ULP were positive for platelet derived growth factor receptoralpha (PDGFR), caveolin-1 and 2, phosphorylated and non-phosphorylated Cx43 but negative for the stem cell marker CD34. In contrast, ICs in the DLP were positive for vimentin, CD34 and non-phosphorylated Cx43 but negative for aSMCA, caveolin-1 and 2, PDGFR. Both populations of interstitial cell populations were negative for c-kit ${ }^{4}$. While the functional aspects of those patchwork-like findings still must be established, 
there is a clear indication of the high relevance of the interstitial cells in the lamina propria.

\section{Methodical aspects / Limitations}

FIB-SEM and / or 3View SEM are important techniques to gather ultrastructural volume data at high resolution from biological tissues. Missing of deformation by compression is a major advantage of blockface imaging compared to ultrathin sectioning. In addition, only secondary electrons of the very surface and in few $\mathrm{nm}$ of depth are used for imaging. This provides very thin slices of the tissue which, however, compromises the contrast of the image. Special electron collection techniques are necessary for improvement of signal-to-noise-ratio. We received best results by using a combination of backscattered electrons (BSE) with an energy selective backscattered electron (ESB)-detector and an in-lens secondary electron (SE) detector. The major limitation of our study is that only a small number of samples could be analyzed by 3Dultrastructure reconstruction, due to the time-consuming manual segmentation.

\section{Conclusions:}

We could reveal new morphological features of interstitial cells in the ULP of the human bladder. Our findings support the notion of a homocytic functional syncytium between ICs with myoid differentiation (mICs) by coupling via tiny Cx43-positive GJs. Those cells also expressed the FNEDA domain, which is thought to be characteristic for myofibroblasts and might be of functional relevance due to involvement in various signaling pathways. Typical telocytes were not present in our specimens. The stellate cell with ICC-like features made contacts to urothelial cells. This is to our best knowledge the first report of such heterocellular contacts in the human urinary bladder.

\section{References:}

1. Kanai A, Fry C, Hanna-Mitchell A, Birder L, Zabbarova I, Bijos D, Ikeda Y. Do we understand any more about bladder interstitial cells?-ICl-RS 2013. Neurourol Urodyn 2014; 33(5):573-576. doi:10.1002/nau.22591. 
2. Andersson KE, McCloskey KD. Lamina propria: the functional center of the bladder? Neurourol Urodyn 2014; 33(1):9-16. doi:10.1002/nau.22465.

3. Cheng S, Scigalla FP, Speroni di Fenizio P, Zhang ZG, Stolzenburg JU, Neuhaus J. ATP enhances spontaneous calcium activity in cultured suburothelial myofibroblasts of the human bladder. PLoS One 2011; 6(10):e25769. doi:10.1371/journal.pone.0025769.

4. Gevaert T, De Vos R, Van Der Aa F, Joniau S, van den Oord J, Roskams T, De Ridder D. Identification of telocytes in the upper lamina propria of the human urinary tract. J Cell Mol Med 2012; 16(9):2085-2093. doi:10.1111/j.15824934.2011.01504.x.

5. Deerinck TJ, Bushong EA, Thor A, Ellisman MH. NCMIR methods for 3D EM: a new protocol for preparation of biological specimens for serial block face scanning electron microscopy. center for research in biological systems and the national center for microscopy and imaging research, university of california, san diego, la jolla, ca, usa; 2013. available from: http://ncmir.ucsd.edu/sbfsem-protocol.pdf, accessed on 2013-09-11

6. Rasband WS. ImageJ. U. S. National Institutes of Health, Bethesda, Maryland, USA, http://rsb.info.nih.gov/ij/, 1997-2016

7. Faussone Pellegrini MS, Popescu LM. Telocytes. Biomol Concepts 2011; 2(6):481-489. doi:10.1515/BMC.2011.039.

8. Glukhova MA, Frid MG, Shekhonin BV, Balabanov YV, Koteliansky VE. Expression of fibronectin variants in vascular and visceral smooth muscle cells in development. Dev Biol 1990; 141(1):193-202.

9. Sui GP, Wu C, Roosen A, Ikeda Y, Kanai AJ, Fry CH. Modulation of bladder myofibroblast activity: implications for bladder function. Am J Physiol Renal Physiol 2008; 295:688-697. doi:10.1152/ajprenal.00133.2008. 
10. Sui GP, Rothery S, Dupont E, Fry CH, Severs NJ. Gap junctions and connexin expression in human suburothelial interstitial cells. BJU Int 2002; 90(1):118-129.

11. Neuhaus J, Pfeiffer F, Wolburg H, Horn LC, Dorschner W. Alterations in connexin expression in the bladder of patients with urge symptoms. BJU Int 2005; 96(4):670676.

12. Eyden B. The Myofibroblast. A study of normal, reactive and neoplastic tissues, with an emphasis on ultrastructure. Journal of Submicroscopic Cytology and Pathology 2007; 7-166.

13. Okamura Y, Watari M, Jerud ES, Young DW, Ishizaka ST, Rose J, Chow JC, Strauss JF. The extra domain A of fibronectin activates Toll-like receptor 4. J Biol Chem 2001; 276(13):10229-10233. doi:10.1074/jbc.M100099200.

14. Serini G, Bochaton-Piallat ML, Ropraz P, Geinoz A, Borsi L, Zardi L, Gabbiani G. The fibronectin domain ED-A is crucial for myofibroblastic phenotype induction by transforming growth factor-beta1. J Cell Biol 1998; 142(3):873-881.

15. Gevaert T, de Ridder D, Vanstreels E, Daelemans D, Everaerts W, van der Aa F, Pintelon I, Timmermans JP, Roskams T, Steiner C, Neuhaus J. The stem cell growth factor receptor KIT is not expressed on interstitial cells in bladder. J Cell Mol Med 2016; XX1-11.

16. Rasmussen H, Rumessen JJ, Hansen A, Smedts F, Horn T. Ultrastructure of Cajallike interstitial cells in the human detrusor. Cell Tissue Res 2009; 335(3):517-527. doi:10.1007/s00441-008-0736-z.

17. Rusu MC, Nicolescu MI, Jianu AM, Lighezan R, Mănoiu VS, Păduraru D. Esophageal telocytes and hybrid morphologies. Cell Biol Int 2012; 36(12):10791088. doi:10.1042/CBI20120007. 
18. Kanai A, Fry C, Ikeda Y, Kullmann FA, Parsons B, Birder L. Implications for bidirectional signaling between afferent nerves and urothelial cells-ICI-RS 2014. Neurourol Urodyn 2016; 35(2):273-277. doi:10.1002/nau.22839.

19. Fry $\mathrm{CH}$, Sui GP, Kanai AJ, Wu C. The function of suburothelial myofibroblasts in the bladder. Neurourol Urodyn 2007; 26(6 Suppl):914-919. doi:10.1002/nau.20483.

20. Birder L, Andersson KE. Urothelial signaling. Physiol Rev 2013; 93(2):653-680. doi:10.1152/physrev.00030.2012.

21. Ikeda Y, Fry CH, Hayashi F, Stolz DB, Griffiths D, Kanai AJ. The Role of Gap Junctions in Spontaneous Activity of the Rat Bladder. Am J Physiol Renal Physiol 2007; F1018-25.

22. Sui GP, Coppen SR, Dupont E, Rothery S, Gillespie J, Newgreen D, Severs NJ, Fry $\mathrm{CH}$. Impedance measurements and connexin expression in human detrusor muscle from stable and unstable bladders. BJU Int 2003; 92(3):297-305. 


\section{Supplemental Methods}

Specimens included were derived from 72y (male, cystectomy), 65y (male, transurethral bladder biopsies) and a 53y (female, cystectomy) patient containing macroscopic and microscopic unaltered bladder tissue. Specimens were processed for standardized paraffin embedding using a DDM-P801 and P063 embedding machine (MEDIM, Gießen, Germany). Multiplex immunofluorescence was done in 10$30 \mu \mathrm{m}$ thick paraffin sections using the antibody panel in combination Alexa Fluor ${ }^{\circledR}$ 488-labelled wheat germ agglutinin (WGA488) binding to sialic acid and $\mathrm{N}$ acetylglucosaminyl residues, respectively (Table S1). We used anti-smooth muscle cell actin antibody to identify interstitial cells with myoid differentiation (mIC), anti-connexin 43 to depict gap junctions (GJ), and an antibody against the ED-A domain of fibronectin to label cellular fibronectin for identification of fibronexus.

Sections were de-paraffinized, rehydrated and processed for antigen retrieval in target retrieval solution pH 9 (DAKO, Glostrup, Denmark) for 30 min at $100^{\circ} \mathrm{C}$ in a steamer (Braun, Kronberg, Germany). Slices were then washed in phosphate-buffered saline ( $\mathrm{pH}$ 7.4) and transferred to Tris-buffered saline (50 mM TBS, $\mathrm{pH} 7.4$ ). Following treatment with TBS (0.1\% Triton X-100) for 10 min and blocking unspecific binding (TBS, $0.1 \%$ Triton X-100, 1\% bovine serum albumin, 3\% fat-free milk powder) for 30 min at room temperature, slices were incubated overnight in a cocktail of primary antibodies. Following $3 x$ washes in TBS slices were incubated with appropriate secondary antibodies for $1 \mathrm{~h}$ at room temperature. After washing in TBS slices were incubated for $2 \mathrm{~h}$ at RT with WGA488 (1:200 in TBS). Nuclei were counter stained either with TO-PRO®-3 lodide (Thermo Fisher Scientific, Rockford, IL, USA) or DAPI (SigmaAldrich, Steinheim, Germany.

Confocal laser scanning image stacks were acquired at a LSM 700 (Carl Zeiss Microscopy, Göttingen, Germany) equipped with 405nm, 488nm, 555nm and 639nm laser diodes. The scan parameters were: Plan-Apochromat 40x/0.95 Korr; voxel size (xyz) $64 \mathrm{~nm} \times 64 \mathrm{~nm} \times 177 \mathrm{~nm}$; pinhole of $50.1 \mu \mathrm{m}, 43.5 \mu \mathrm{m}, 38.5 \mu \mathrm{m}$ at excitation wavelength of $639 \mathrm{~nm}, 555 \mathrm{~nm}$ and $488 \mathrm{~nm}$, respectively; Plan-Apochromat 63x/1.4 oil; voxel size (xyz) $41 \mathrm{~nm}$ x $41 \mathrm{~nm}$ x $131 \mathrm{~nm}$; pinhole of $53.9 \mu \mathrm{m}, 46.6 \mu \mathrm{m}, 41.1 \mu \mathrm{m}$ at excitation wavelength of $639 \mathrm{~nm}, 555 \mathrm{~nm}$ and $488 \mathrm{~nm}$, respectively. Stack sizes varied between 60 and 80 images. Image deconvolution and 3D-reconstruction were done with Huygens Essential imaging software package (SVI Scientific Volume Imaging, Hilversum, The Netherlands) or image ${ }^{10}$. 
Table 1: Immunolabels used for confocal laser scanning microscopy

\begin{tabular}{lllll}
\hline Primary antibodies & host & source & order-no & dilution \\
\hline alpha-smooth muscle cell actin & rabbit & {$[1]$} & ab5694 & $1: 200$ \\
alpha-smooth muscle cell actin & mouse, IgG2a & {$[2]$} & A2547 & $1: 2000$ \\
connexin 43 (Cx43) & rabbit & {$[2]$} & C6219 & $1: 500$ \\
Fibronectin, FN ED-A [IST-9] & mouse, IgG1 & {$[3]$} & ab6328 & $1: 200$ \\
\hline Secondary antibodies / WGA & source & order-no & dilution \\
\hline Alexa Fluor ${ }^{\circledR}$ 488 goat anti-mouse IgG2a & & & A-21131 & $1: 500$ \\
Alexa Fluor ${ }^{\circledR}$ 555 goat anti-rabbit & {$[3]$} & A-21428 & $1: 500$ \\
Alexa Fluor ${ }^{\circledR}$ 633 goat anti-rabbit & {$[3]$} & A-21070 & $1: 500$ \\
Wheat Germ Agglutinin, Alexa Fluor & 488 & {$[3]$} & W11261 & $1: 200$ \\
\hline
\end{tabular}

Nuclear staining

TO-PRO®-3 Iodide (642/661)

DAPI

(4',6-Diamidine-2'-phenylindole dihydrochloride)

[3]

T3605

$1: 750$

[2]

$1: 5000$

[1] Abcam Inc., Cambridge, USA

[2] Sigma-Aldrich Chemie GmbH, Steinheim, Germany

[3] Thermo Fisher Scientific, Rockford, IL, USA 
Table S2: Ultrastructural features of interstitial cells revealed by 3View-FE-SEM

Code: $\mathrm{mIC}=$ myoid IC; flC=fibroblast type IC; bIC=branched IC; CYT=cytoplasm; NUC=nucleus; MF=micro filaments;

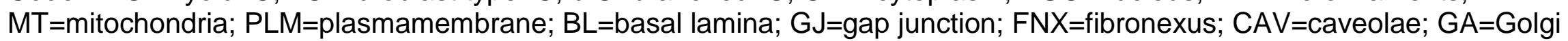
apparatus; $\mathrm{CP}=$ coated pits / vesicles; $\mathrm{GJ}$ between cells are indicated by referencing the number of the cell in the ,GJ'-column.

\begin{tabular}{|c|c|c|c|c|c|c|c|c|c|c|c|c|c|c|}
\hline Label & cell type & CYT & NUC & $\mathrm{MF}$ & MT & PLM & $\mathrm{BL}$ & GJ & FNX & CAV & GA & $\mathrm{CP}$ & rER & Lipofuscin \\
\hline IC1 & $\mathrm{mIC}$ & $\begin{array}{c}\text { pale, } \\
\text { moderate }\end{array}$ & double, pale & + & $\begin{array}{c}\text { moderate } \\
\text { throughout } \\
\text { CYT }\end{array}$ & uneasy & - & $\stackrel{+}{\text { IC9 }}$ & + & + & ++ & - & $\begin{array}{l}\text { incon- } \\
\text { spicuous }\end{array}$ & - \\
\hline IC2 & $\mathrm{mIC}$ & pale & na & +++ & few & uneasy & - & $\stackrel{+}{\mathrm{IC} 13}$ & +++ & - & - & - & $\begin{array}{l}\text { incon- } \\
\text { spicuous }\end{array}$ & \\
\hline IC3 & blc & dark, sparse & dark & - & $\begin{array}{c}\text { many, } \\
\text { perinuclear } \\
\text { and at } \\
\text { branching } \\
\text { points }\end{array}$ & smooth & $\begin{array}{c}+ \\
\text { disconti } \\
\text { neous }\end{array}$ & $\begin{array}{c}+ \\
\text { urothelial } \\
\text { cells }\end{array}$ & - & - & small & - & $\begin{array}{l}\text { incon- } \\
\text { spicuous }\end{array}$ & - \\
\hline IC4 & Lymphocyte & $\begin{array}{c}\text { pale, } \\
\text { moderate }\end{array}$ & $\begin{array}{l}\text { hetero- } \\
\text { chromatin }\end{array}$ & - & few & smooth & - & - & - & - & - & - & $\begin{array}{l}\text { incon- } \\
\text { spicuous }\end{array}$ & - \\
\hline IC5 & $\mathrm{flC}$ & $\begin{array}{c}\text { pale, } \\
\text { abundant }\end{array}$ & $\begin{array}{c}\text { pale, rounded, } \\
\text { slightly } \\
\text { lobulated } \\
\end{array}$ & - & abundant & smooth & - & $\stackrel{+}{+}$ & - & - & ++ & + & ++ & ++ \\
\hline IC6 & $\mathrm{mIC}$ & $\begin{array}{c}\text { pale, } \\
\text { moderate }\end{array}$ & $\begin{array}{c}\text { large } \\
(20 \times 12 \mu \mathrm{m}) \\
\text { lobulated }\end{array}$ & + & abundant & uneasy & - & $\begin{array}{c}++ \\
\text { IC7 } \\
\text { IC16 } \\
\text { IC10 } \\
\end{array}$ & + & - & ++ & - & - & - \\
\hline IC7 & $\mathrm{mlC}$ & $\begin{array}{c}\text { pale, } \\
\text { moderate }\end{array}$ & oval, indented & ++ & perinuclear & uneasy & - & $\begin{array}{c}+ \\
\text { IC16 } \\
\text { IC6 }\end{array}$ & + & - & small & few & - & - \\
\hline IC8 & $\mathrm{flC}$ & dark & na & - & abundant & \pm smooth & - & $\begin{array}{c}+ \\
\text { IC5 } \\
\text { IC10 } \\
\end{array}$ & - & - & - & - & - & - \\
\hline IC9 & $\mathrm{mlC}$ & pale & na & + & few & uneasy & - & $\stackrel{+}{\mathrm{IC} 1}$ & + & + & - & - & - & \\
\hline IC10 & $\mathrm{mIC}$ & pale & na & ++ & + & uneasy & - & $\stackrel{+}{+}$ & + & + & - & - & - & \\
\hline IC11 & $\mathrm{flC}$ & dark & $\begin{array}{l}\text { dark, hetero- } \\
\text { chromatin }\end{array}$ & - & abundant & smooth & - & - & - & + & - & - & + & - \\
\hline
\end{tabular}




\begin{tabular}{|c|c|c|c|c|c|c|c|c|c|c|c|c|c|c|}
\hline Label & cell type & CYT & NUC & MF & MT & PLM & $\mathrm{BL}$ & GJ & FNX & CAV & GA & $\mathrm{CP}$ & rER & Lipofuscin \\
\hline IC12 & $\mathrm{fIC}$ & dark & na & - & + & \pm smooth & - & - & - & - & - & - & ++ & - \\
\hline IC13 & $\mathrm{mIC}$ & pale & indented & ++ & $\stackrel{+}{+} \underset{\text { long, small }}{ }$ & uneasy & - & $\begin{array}{l}++ \\
\text { IC2 }\end{array}$ & + & + & $\begin{array}{c}+ \\
\text { incon- } \\
\text { spicuous }\end{array}$ & - & $\begin{array}{l}\text { incon- } \\
\text { spicuous }\end{array}$ & - \\
\hline IC14 & $\mathrm{flC}$ & dark & na & - & + & $\begin{array}{l} \pm \text { smooth } \\
\text { few } \\
\text { vesicles }\end{array}$ & - & - & - & - & 1 & - & ++ & + \\
\hline IC15 & $\mathrm{mlC}$ & pale & $\begin{array}{c}+ \\
+ \\
\text { slightlly } \\
\text { indented }\end{array}$ & ++ & + & uneasy & - & $\stackrel{+}{\text { IC6 }}$ & + & + & $\begin{array}{c}+ \\
\text { incon- } \\
\text { spicuous } \\
\end{array}$ & - & - & - \\
\hline IC16 & $\mathrm{mlC}$ & pale & na & + & $\begin{array}{c}++ \\
\text { small }\end{array}$ & uneasy & - & - & - & + & - & - & - & - \\
\hline IC17 & $\mathrm{mIC}$ & pale & + & + & $\begin{array}{c}++ \\
\text { small }\end{array}$ & uneasy & - & - & - & + & $\begin{array}{c}+ \\
\text { incon- } \\
\text { spicuous }\end{array}$ & + & + & - \\
\hline
\end{tabular}



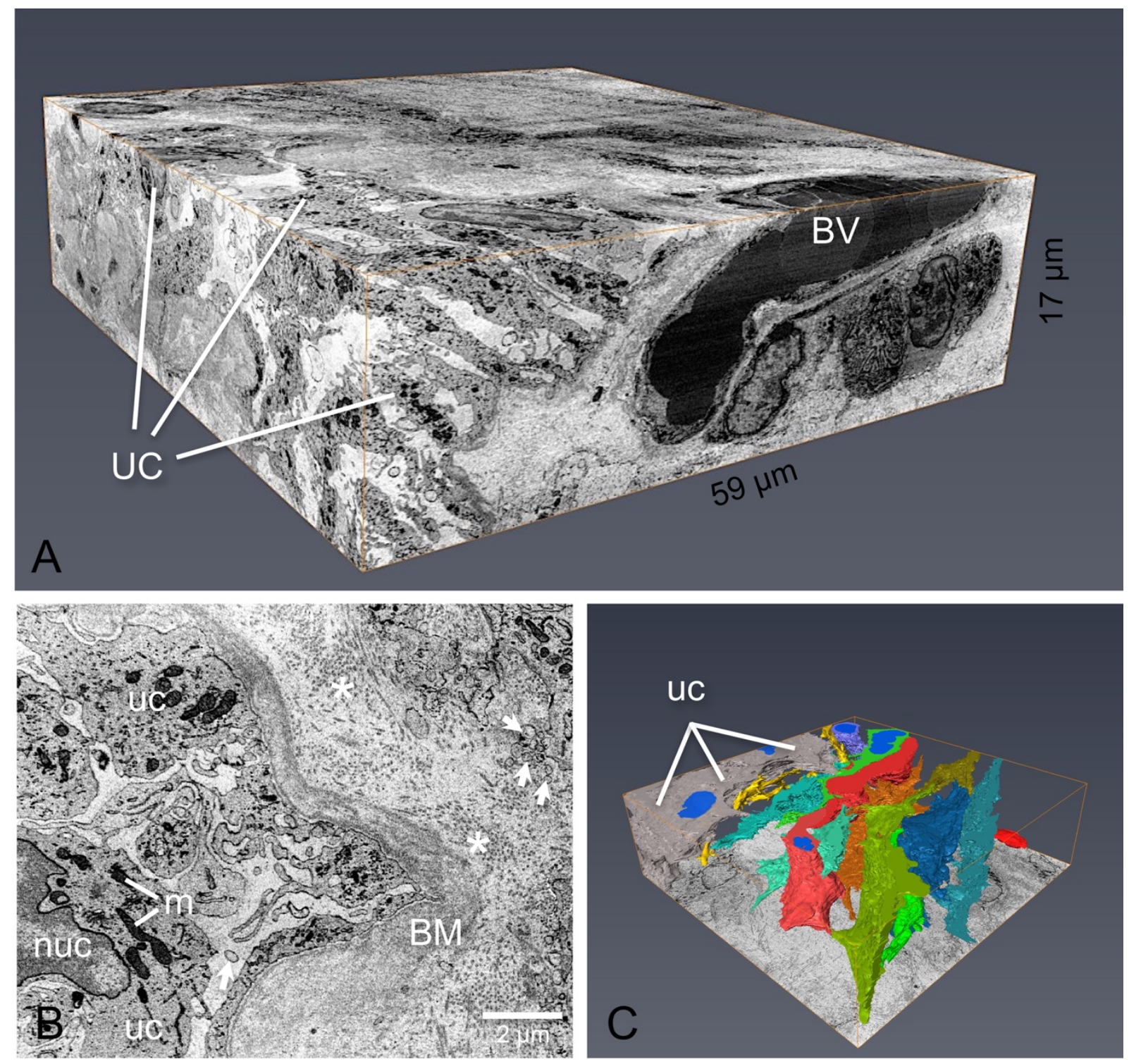

Figure 1: 3View-SEM stack of $59 \mu \mathrm{m} \times 59 \mu \mathrm{m} \times 17 \mu \mathrm{m}$. (A) Tissue block reconstructed from 349 block-face SEM images spaced by $50 \mathrm{~nm}$ at a pixel size of $16 \mathrm{~nm} \times 16 \mathrm{~nm}$; UC = urothelial cells; BV = blood vessel; $(\mathbf{B})$ is characterized by massive collagen I bundles (asterisks) containing ECM and abundant cell membranes; note the numerous small diameter vesicle like membranes (arrows; $B M=$ basal membrane, nuc = nucleus, $\mathrm{m}=$ mitochondrion); (C) 3D reconstruction of $\mathrm{mIC}$ impress by a flat sheet-like morphology with the flattened surface facing the urothelium; for visualization single cell surfaces are color-coded; bIC = yellow; fIC = red color; $\mathrm{mIC}=$ dark green, green, light-green, olive-green, orange, dark-blue; nuclei = blue. 

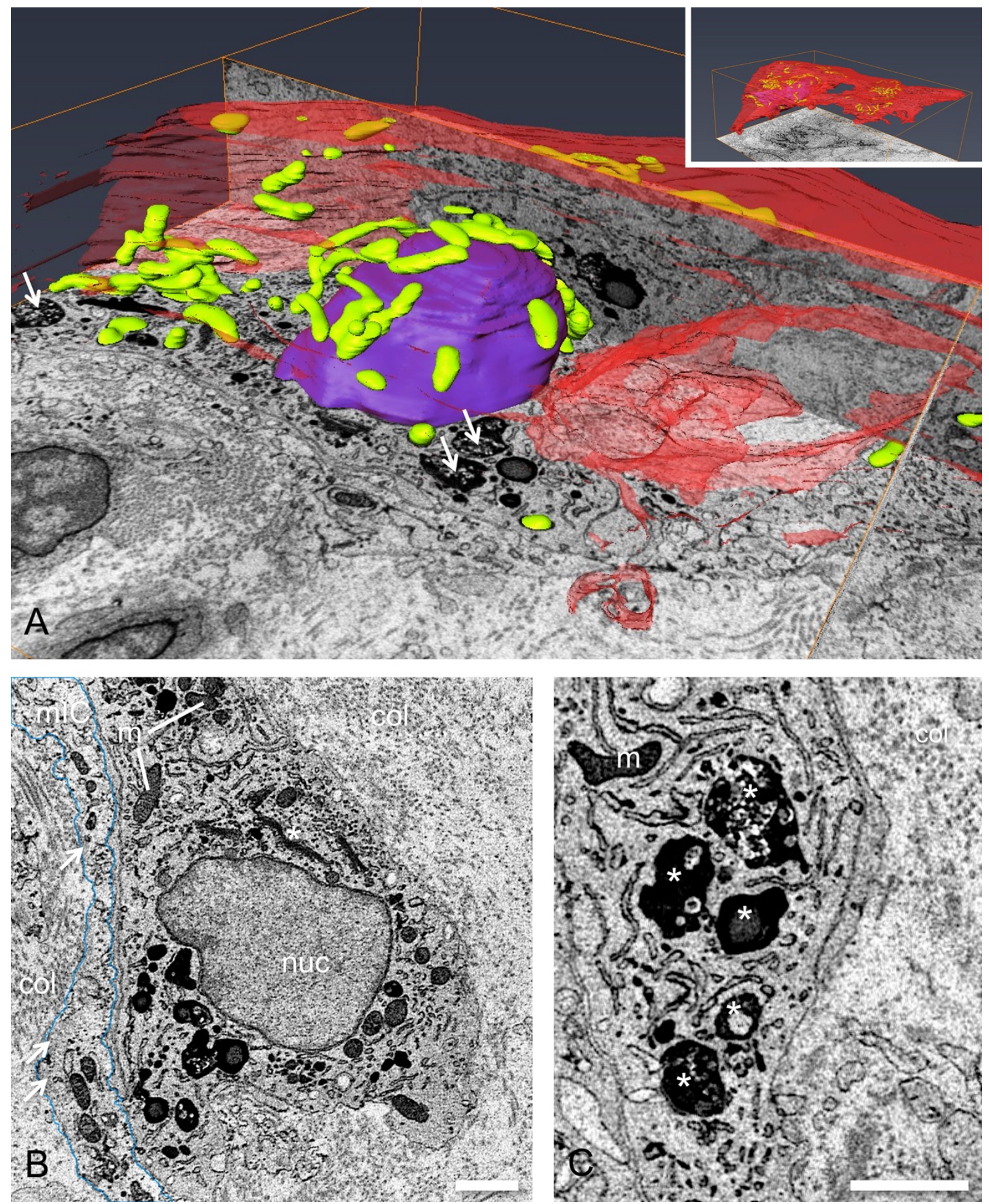

Figure 2: Activated fIC in upper lamina propria. (A) 3D-reconstruction with nucleus (blue), mitochondria (lime green), plasmalemma (red) and autophagosomes (arrows); inset=complete cell. (B) Note the large cell body containing groups of small mitochondria (m), prominent ER (rER, asterisk) and a pale nucleus (nuc) with only few peripheral heterochomatin; the cytoplasm of the $\mathrm{fIC}$ is darker than those of an adjacent myoid interstitial cell (mIC, light blue surface label) identified by sub-plasmalemma microfilament bundles (arrows); col = collagen; (C) the smooth plasmalemma shows 
no sub-plasmalemmal densities or microfilaments and is not covered by a basal lamina. No caveolae were detected; large irregular lipofuscin granules (asterisks); scale bars $=2 \mu \mathrm{m}$. 

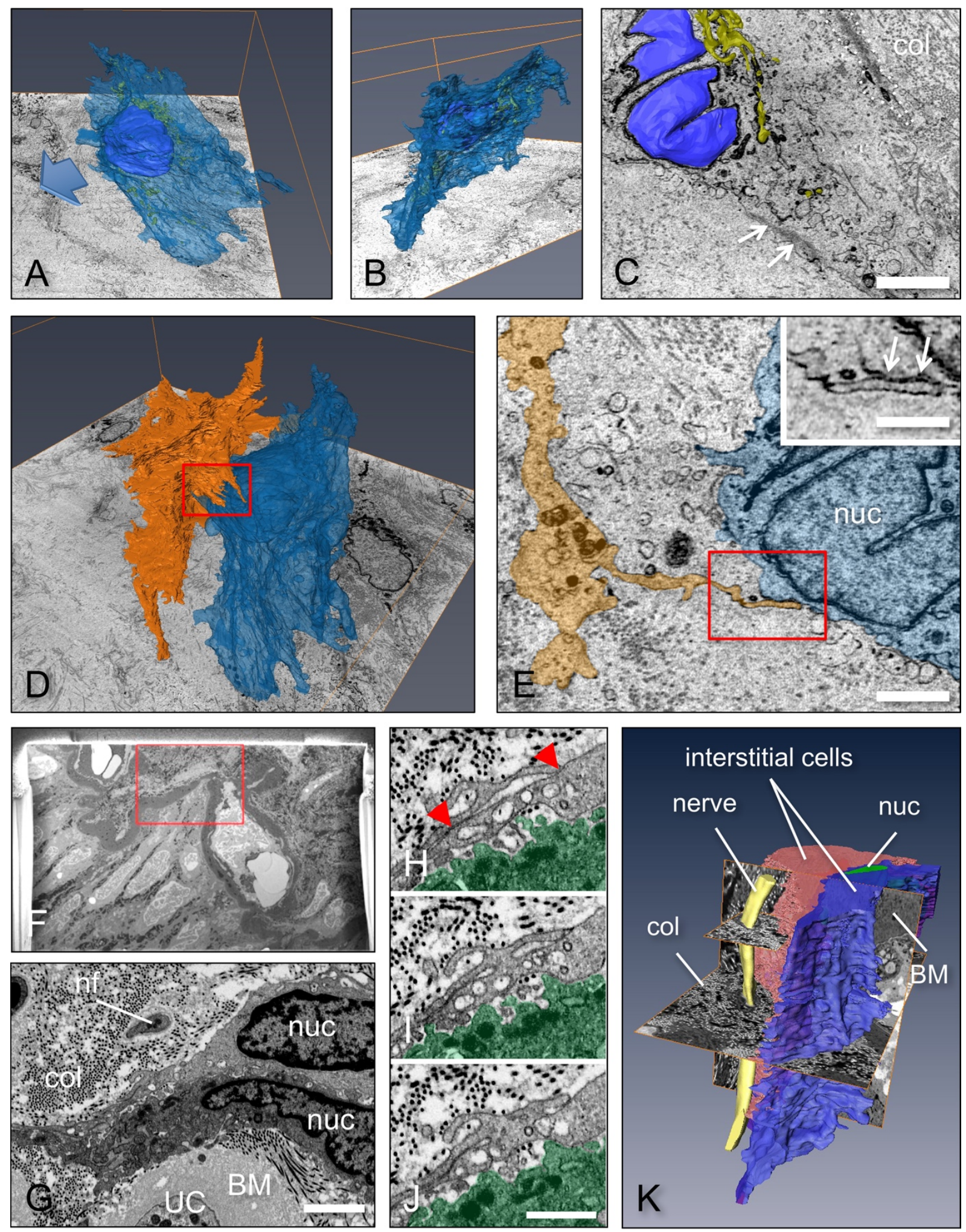

Figure 3: Morphology and ultrastructural features of ICs in the upper lamina

propria. (A) mIC with a maximum thickness of about $10.5 \mu \mathrm{m}$ at nuclear level and thin (1-4 $\mu \mathrm{m})$, flat cell body (B); blue arrow in (A) indicates urothelial face direction. (C) This cell shows numerous sub-plasmalemmal microfilament bundles (arrows). Note the numerous small vesicles in the extracellular space close to the plasma membrane. Right hand another mIC, characterized by microfilaments, is visible (dashed line); 
nucleus $=$ blue $;$ mitochondria $=$ yellow; collagen $=$ col; scale bar $=4 \mu \mathrm{m} ;(D)$ adjacent mIC (orange) demonstrating the same features; (E) where the cells come into close contact they form GJs (arrows, inset scale bar = $1 \mu \mathrm{m}$ ); scale bar = $2 \mu \mathrm{m}$; $(\mathbf{F})$ overview showing the slot prepared perpendicular to the sample surface for FIB blockface imaging. Further preparation is limited to the area demarked by red frame. (G) blockface imaging at high resolution (pixel size: $4.948 \mathrm{~nm} \times 4.948 \mathrm{~nm}$; = $15.2 \mu \mathrm{m}$ x $11.4 \mu \mathrm{m}$ image size); scale bar $=2 \mu \mathrm{m}$; 990 images were scanned at $10 \mathrm{~nm}$ intervals (9.9 $\mu \mathrm{m}$ in depth); (H-J) detailed analysis of GJs between the two connected cell protrusions revealed homocytic junctions between the protrusions of a single cell; note that there is no connection to the green labeled neighboring cell; scale bar $=1 \mu \mathrm{m}(\mathrm{K})$ 3D-reconstruction of the two suburothelial interstitial cells and a presumable nerve fiber passing by; urothelium (UC), basal membrane (BM), nuc = nucleus, col = collagen. 

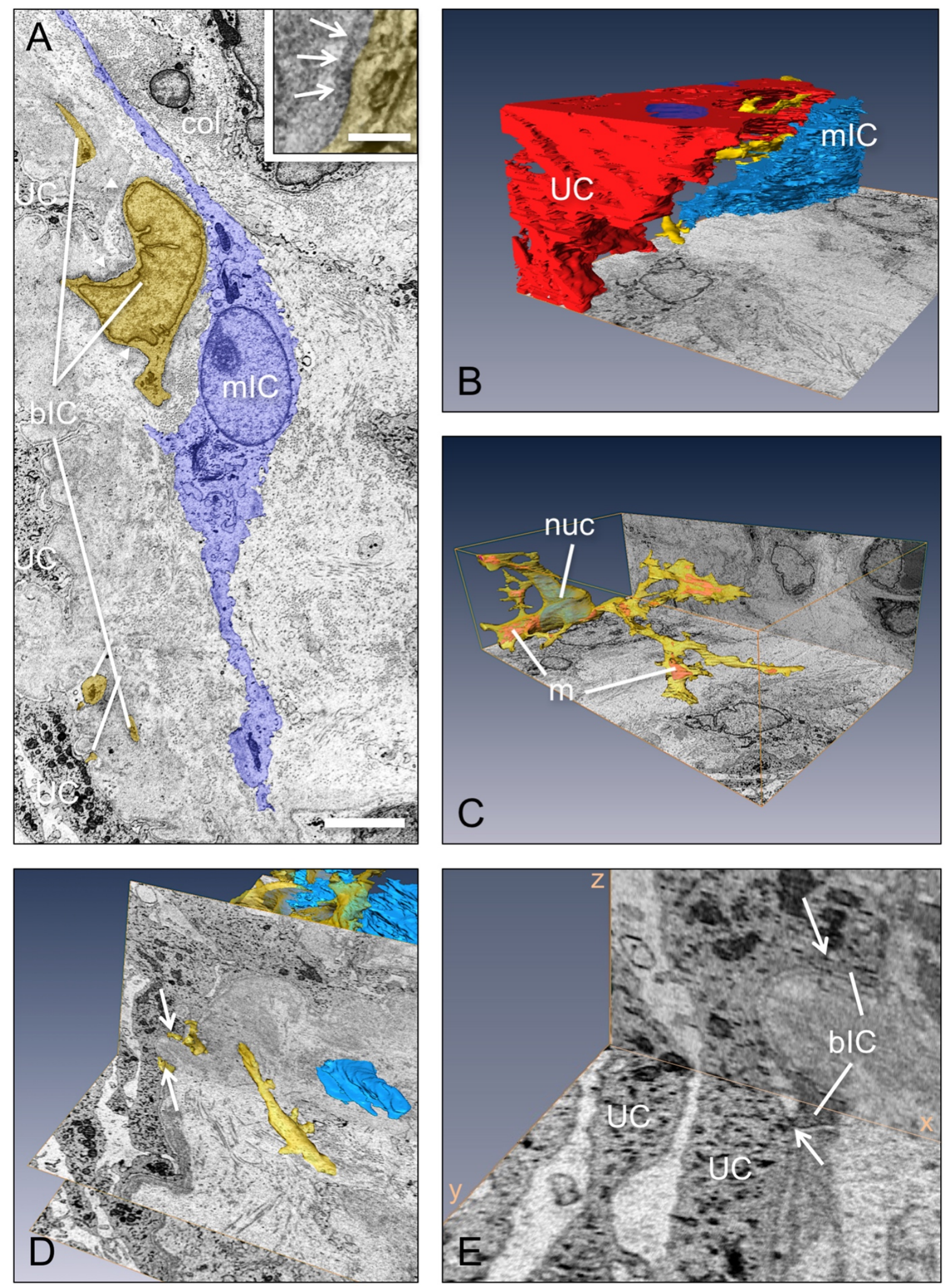

Figure 4: Branched interstitial cell (bIC) in the upper lamina propria. (A) original SEM blockface image showing a mIC (light blue) and several cuts of the bIC (yellow); one tiny protrusion comes very close to the $\mathrm{UC}$; the cell is covered by an interrupted basal lamina (arrow heads); scale bar $=5 \mu \mathrm{m}$; inset: bIC cell membrane with 
discontinuous basal lamina (arrows); nuc = nucleus; scale bar $=1 \mu \mathrm{m}$; (B) 3Dreconstruction of the scene indicating the spatial relations of the $\mathrm{mIC}$ (blue) and the bIC (yellow) to the urothelium (red); (C) full 3D-reconstruction of the bIC demonstrating the extraordinary cell morphology, completely different from the other ICs; the small cell body is occupied by the nucleus (blue) and mitochondria (red) are located at the branching points of the 3-4 cell branches; (D-E) close up of the junction-like connection of tiny bIC protrusions with an UC (arrows); xyz-axes are indicated in $(E)$; $U C=$ urothelial cell; nuc = nucleus; $\mathrm{m}=$ mitochondrion; $\mathrm{col}=$ collagen . 

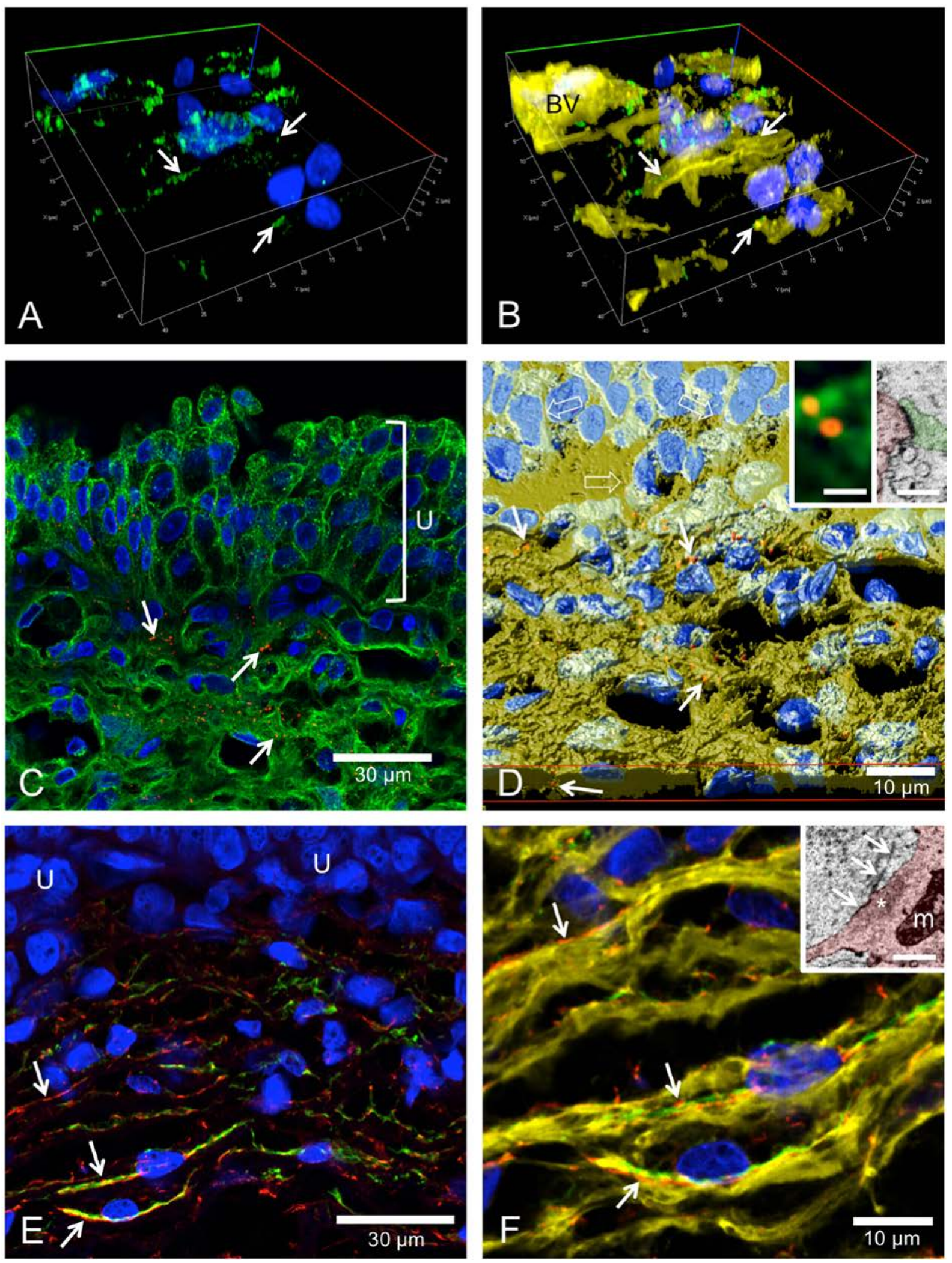

Figure 5: Immunohistological characterization of ICs. (A-B) 3D-reconstruction of alpha-smooth muscle cell actin (aSMCA; green) positive mICs; nuclei (blue); cell morphology can hardly be determined; (B) WGA plasma membrane labelling (yellow) reveals flat morphology of the mICs (arrows); BV = blood vessel; (C-D) numerous Cx43 positive GJs between ICs in the ULP (filled arrows) and some few GJs between 
urothelial cells are visible (open arrows); (C) one slice from confocal stack; (D) 3Dreconstruction of 45 images confocal stack; left inset: Cx43+ labels in CLSM; right inset: SEM image of a GJ between two $\mathrm{mIC}$; bar $=1 \mu \mathrm{m}$; (E-F) maximum intensity projection of cellular fibronectin EDA domain (FNEDA, red), aSMCA (green) and WGA (yellow); FNEDA labelling is restricted to the IC of the ULP; colocalization with aSMCA is in agreement with the ultrastructural findings of sub-plasmalemmal microfilaments and adjacent fibronectin (arrows); (F) higher magnification and depiction of WGA (yellow) in tilted 3D-reconstruction confirms the plasmalemmal localization of most FNEDA labels (arrows); inset: ultrastructural appearance of fibronexus (arrows); microfilaments (asterisk); bar $=1 \mu \mathrm{m} ; \mathrm{U}=$ urothelium; $\mathrm{m}=$ mitochondrion. 

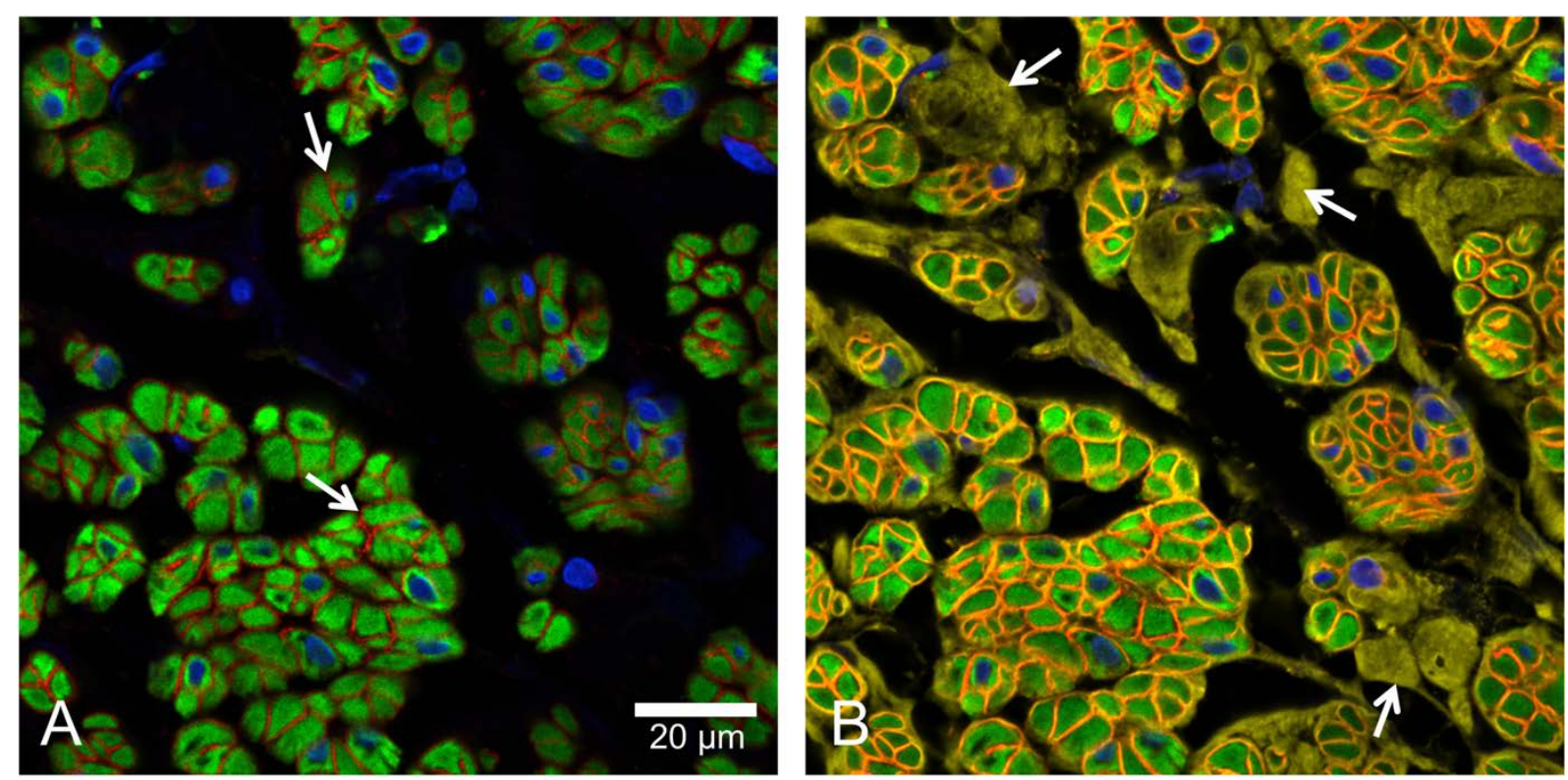

Supplemental Figure S1: FNEDA labelling in detrusor serving as positive tissue control $^{9}$. (A) FNEDA (red, arrows) is expressed exclusively between detrusor smooth muscle cells, identified by aSMCA (green); nuclei = blue; (B) merged with WGA (yellow) revealing FNEDA-free non-muscle cells (arrows).

\section{Not available on this server}

Supplemental Video S1: 3D-reconstruction of 10 cells from $59 \times 59 \times 17 \mu \mathrm{m}$ tissue block. Note the flat, pancake-like appearance and strict parallel orientation to the urothelium. The branched IC facing the urothelium is characterized by 3 major branches emerging from a small cell body. Nucleus is blue colored and the mitochondria in pink. Note the accumulation at the branching points.

Supplemental Video S2: 3D-reconstruction from confocal image series in Figure 7B. Plasma membranes are labelled by WGA (yellow) providing an improved impression of cell morphology than aSMCA (green) labelling. 